\author{
Military Technical College \\ Kobry El-Kobbah, \\ Cairo, Egypt
}

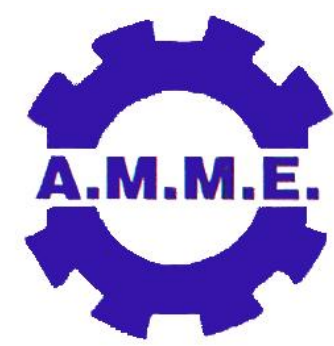

$14^{\text {th }}$ International Conference on

Applied Mechanics and

Mechanical Engineering.

\title{
Macroscopic and Microscopic Aspects Observed in Composite Processing For Shape Memory Alloy
}

\author{
By
}

Bakr Mohamed Rabeeh *

\begin{abstract}
:
Brass-Al-Brass foils hot isostatically pressed, HIPPed, at solid state for lamellar composite processing. However, it resolves lamellar composite structures, macroscopic and microscopic evidence of shape memory, SMA, alloys are established. The arrangement and architectural behavior of metal matrix composite introduced, however it has a potential effect on the final structure. Ply number as well as design assembly are dominant for either lamellar metal matrix composite or delocalized shape memory alloy embedded within composite structure. This phenomenon is rarely observed in lamellar composite processing or in $\mathrm{Cu} \mathrm{Zn} \mathrm{Al} \mathrm{SMA.} \mathrm{The} \mathrm{macrostructurall} \mathrm{analysis} \mathrm{performed} \mathrm{on} \mathrm{the} \mathrm{HIPPed} \mathrm{structures}$ showed the possibilities for the application of this technique in copper based shape memory alloy. Microstructural observations resolved not only a good interface for bulk joints, but dominant zone of interest ( clear interphase, copper inriched zones, aluminum inriched zones as well as copper-zinc-alumin shape memory ply). Parametric study of a hot isostatic pressing approach in a solid state processing is conducted for the assessment of a new emerging Cu-Zn-Al shape memory alloy delocalized and embedded within lamellar structure. The interphase kinetic of Cu-Zn-Al metal matrix composite as well as effect of alloying elements on composite processing are introduced. Microstructure characterization established with scanning electron microscopy and energy dispersive X-ray spectroscopy, EDX. The results showed that very regular delocalized enriched zones of interests could be obtained in a composite having an interphase morphology and relative percent of alloying elements. Microstructural and compositional analyses on composite specimens showed symmetrical and uniform delocalized microstructure. In this way the possibility of formation of $\mathrm{Cu}-\mathrm{Zn}-\mathrm{Al}$ system either with or without lamellar composite structure processing through the proposed low-cost process is clearly demonstrated. This alloy is produced through a recently proposed HIPing process, which consists mainly of a controlled lamellar architecture in a solid state processing.
\end{abstract}


* German University in Cairo, Engineering and Materials Science Department.

\section{Introduction:}

The intermetallic $\mathrm{Cu}-\mathrm{Zn}-\mathrm{Al}$ has been considered for many applications as a consequence of low density high thermal conductivity and high specific modulus and good creep, fatigue $[1,2]$. Aluminum-brass (copper-zinc) foils have been solid-state bonded with different hot pressing parameters and different architecture. The bondability is controlled and improved by diffusion, since good surface contact is achieved at relatively low temperature and pressure, although the resulting bond line microstructures are influenced by the diffusion of the interlayers. Different architectures arranged in a lamellar form induced macroscopic and microscopic differences. Parametric study established to reveal the effect of time, temperature and pressure on lamellar structure composite. However, equal ply thickness are lay-up in a symmetrical way five plies, macroscopic evidence established with new engineered hybrid composite. The effect of zinc in brass laminate induced new composite morphology as well as delocalized zones of interest, Cu-Zn-Al alloy. Different approach of alloying elements segregation induced different microstrucal observation in $\mathrm{Cu}-\mathrm{Zn}$-Al alloy. SEM as well as EDS established to study micro structural constituents as well as new interphase morphology.

Despite of growing list of alloys that display shape memory effect only two alloy systems have achieved any level of commercial exploitation. These are NiTi (nickel-titanium) and copperbased alloys. Properties of both systems are quite different. The NiTi alloys have greater shape memory strain (up to $8 \%$ versus $4-5 \%$ for the copper-based alloys), tend to be much more thermally stable, have excellent corrosion resistance and have much higher ductility. On the other hand, the copper-based alloys are much less expensive, exhibit higher actuation temperatures (approximately in the range -200 to $+200{ }^{\circ} \mathrm{C}$ ) than NiTi alloys and are sometimes the only choice for high temperature applications (i.e. above $100{ }^{\circ} \mathrm{C}$ ) $[3,4]$. Copper-based shape memory alloys have the advantage that they are made from relatively cheap materials using conventional metallurgical processes such as induction melting. Martensite formation temperatures, Ms, for ternary (three-element) alloys of copper, zinc and aluminium can be made to vary over more than $400^{\circ} \mathrm{C}$ as a result of only small changes in composition. The shape memory alloys all lie in the copper-rich corner of the triangle representing ternary mixtures. The amount of aluminum varies from about 4 to $10 \%$, the amount of zinc from just under 10 to $28 \%[4,5]$.

Commercially pure foils of aluminum are used with eutectic foils of copper-zinc (nearly 34.5 wt. \% Zn). The samples are prepared from foils of $300 \square \mathrm{m}$ thickness and $20 \times 150 \mathrm{~mm}$ width, and $180 \mathrm{~mm}$ length. Brass-Aluminum-Brassr foils are hot pressed as five plies symmetrically from the center. A load of 5 ton is finally used as well as a heating furnace. The hot pressing temperatures of about $500-540^{\circ} \mathrm{C}$ are used. Different holding times are established to fulfill the intermatallic formation (10-30-45- to $60 \mathrm{~min}$.). The force on the joint was kept constant during heating in the furnace by using special fixture. After the prescribed holding time, the set was quickly withdrawn out the furnace and hot pressed, then leaving to cool under the prescribed pressure. Complete solidification results when the melting point depressant (MPD) is reduced from the liquidus compositions to the solidus composition [6]. 
A mass balance is required for converting the liquid interlayer to intermetallic layered and zones of $\mathrm{Cu}-\mathrm{Zn}-\mathrm{Al}$ alloy. The $\mathrm{Cu}-\mathrm{Zn}$ binary alloys are very ductile and have resistance to intergranular fracture as compared to other Cu-based alloys $[7,8]$. These alloys transform to the martensitic state at a temperature below room temperature. Addition of aluminum to the binary alloy can considerably increase the transformation temperatures. Varying the composition of aluminum between $5 \mathrm{wt} . \%$ and $10 \mathrm{wt} . \%$ can shift the $\mathrm{Ms}$ temperature from $-180 \circ \mathrm{C}$ to $100 \circ \mathrm{C}$. However, the parent phase exhibits a strong tendency to decompose into its equilibrium phases when overheated or aged. Due to this, the operating temperatures are typically restricted to approximately $100 \circ \mathrm{C}$ or higher. The transformation temperatures of the alloy are extremely sensitive to composition, and zinc can be lost during the melt process. Due to these factors, the fabrication process of the alloy needs to be precisely controlled.

Illustration of joint foils is shown in Figure 1. $\mathrm{Cu}-\mathrm{Al}-\mathrm{Cu}$ foils are being hot pressed at a temperature lower than the melting point of each. However, the process utilized the study of the different parameters affecting the interplay bonding, new intermetallic $\mathrm{Cu}-\mathrm{Zn}-\mathrm{Al}$ alloy established with a hybrid composite processing. The achievement of the final proper parameters is a complex integration. The interface and interlayers behaviors are investigated as well and diffusion mechanisms and alloying segregation of elements along cross ply. A detailed discussion is included on the microstructural changes, which occur due to diffusion of the interlayers, and their effects on bond properties.

\section{Macroscopic aspects:}

Brass-Al-Brass foils layup, stacked in a symmetrical 5 plies, and then hot isostatic pressed, HIPed in a unidirectional press. These macrostructures are completely different from the parent material structure in the as bonded condition, since a partial diffusion occurs relatively with different hot pressing parameters. The best bonded results that achieved at $500^{\circ} \mathrm{C}$ is being considered at one hour holding time and $50 \mathrm{MPa}$ pressure (Figure 2). However, a clear differences in ply thickness is visible in brass foils. Diffusion mechanism is established at this stage to certain limit. Increasing the pressing temperature, $540^{\circ} \mathrm{C}$, less holding time 45 min., established with $50 \mathrm{MPa}$ pressure resolve different macroscopic aspects (Figure 3) if compared to Fig. 1. This phenomenon attributed to transient liquid phase bonding. Transient liquid phase bonding (TLP) in the general sense implies that equilibrium state of the joint region is solid. The route by which solidification can be achieved, can involve up to four related phenomena. These are diffusion into the joint metals, intermetallic formation, evaporation and extrusion $[9,10]$. The kinetics of TLP bonding is dependent on the rate of removal of the MPD from the interlayer. If the process relies on diffusion onto the bulk, the diffusivity must be on the order of $10^{-8}$ to $10^{-10}$ to produce joint in a reasonable time. As well there must be an element, which forms a deep eutectic with a narrow freezing range which will enhance the kinetics. TLP bond with copper interlayer, which forms the lowest eutectic, must be made above $500^{\circ} \mathrm{C}$, and even at this temperature intermetallic will form.

\section{Microscopic aspects:}

The discrepancy in macroscopic aspects need to be understood with the kinetics of transient liquid phase bonding (TLP). Al-Brass-Al foil HIPped at $540^{\circ} \mathrm{C}$ under $50 \mathrm{MPa}$ press, and for 
different holding time from 10 to 60 minutes. Figure 4, presents Al-Brass-Al at $540^{\circ} \mathrm{C}$ for 10 minutes. a clear dissolution of bras foil with segregation bands are established. However for 30 min more dissolution of brass foil is completely established and dominated by TLP and alloy segregation as presented in Figure 5. Delocalized zone are clearly observed through Al outer plies established. This doesn't reveal a strong evaporation, however extrusion is being considered. This mechanism dominates the central areas in Figure 3 (three ply Al-brass-Al). When considering 5-ply (Fig.3), localized zones of interest are being studied microscopically using energy dispersive X-ray spectroscopy, EDS. The outer ply has a clear interphase, followed by delocalized zones, light zones are $\mathrm{Cu}$-enriched, while white dark zones are Aenriched zones (Fig. 6). An EDX analysis for the different areas of interest such as; the outer surface, the two different interfaces, the two different intermetallic enriched and the center of the sample is presented in Table 1. Transverse segregation morphology og main alloying elements, Copper, zinc and aluminum are obtained via EDS and presented in Figure 7, 8 for Cu distribution and other elements respectively .

EDS analysis is also established for that sample as clear in Figure 7. It reveals the $\mathrm{Cu}$ waveform across the thickness of sample. Besides, an EDS analysis are also performed for different areas of interest such as; the outer surface, the two different interfaces, the two different intermetallic enriched areas and the center of the sample (Table 1). The diffusion behavior of such elements $(\mathrm{Cu}, \mathrm{Al}, \mathrm{Zn}, .$.$) is being considered clearly. A clear diffusion$ behavior of $\mathrm{Zn}$ reveals its directioning towards the outer surfaces. However, a complex mode of bonding mechanisms related to the four different phenomena mentioned before. The interface reveals two layers, Cu-enriched area and Al-enriched area. Outer ply represents copper enriched shape memory alloy with $~ 6 \%$ Al. Zink segregate towards outer ply as TLP within heat extraction. Tensile strength established with $540^{\circ} \mathrm{C}$ sample at $45 \mathrm{~min}$. the stress-strain result reveals a close strength to pure aluminum (Figure 9). Non linear stress strain diagram revealed double yielding and double failure. The strength goes up dramatically exceeding the base metal strength. After these phases begin to diffuse, the strength was insufficient as expected for the presence of brittle $\mathrm{Zn} \times \mathrm{Al}$ phases.

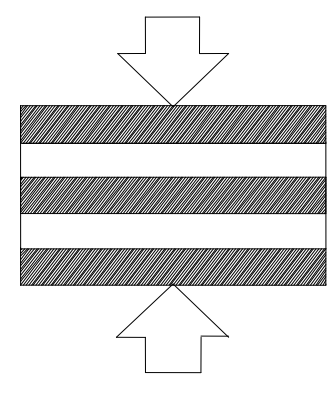

Figure (1) Illustration drawing of Hot Pressed brass-Al-brass Foils sample at constant pressure effect (brass is dark, Al is light). 


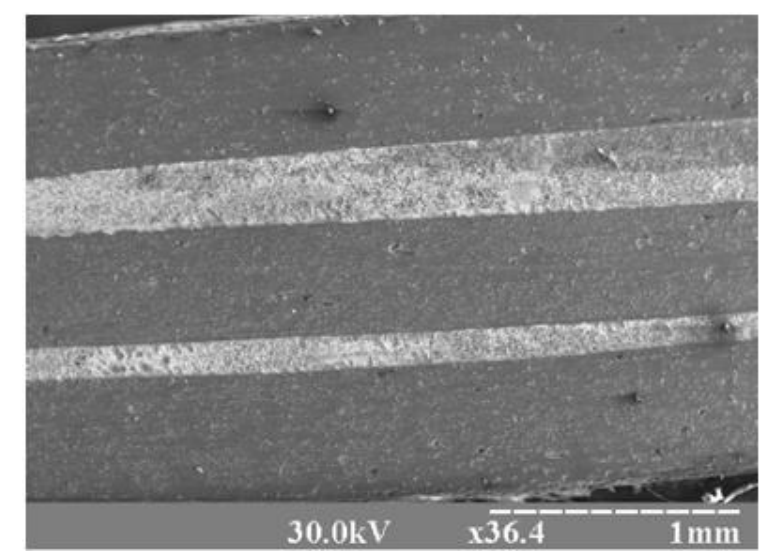

Figure (2): Brass-Aluminum-Brass plies in symmetrical five ply resolve delocalized interfacial melting at $500^{\circ} \mathrm{C}$ and 60 minute holding time.

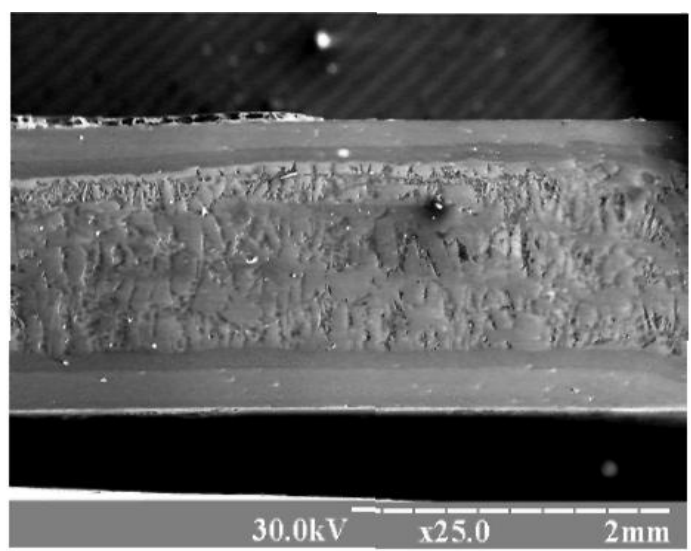

Figure (3): Brass-Aluminum-Brass plies in symmetrical five ply resolve symmetrical ply with delocalized zone at $5400 \mathrm{C}$ and 45 minutes holding time.

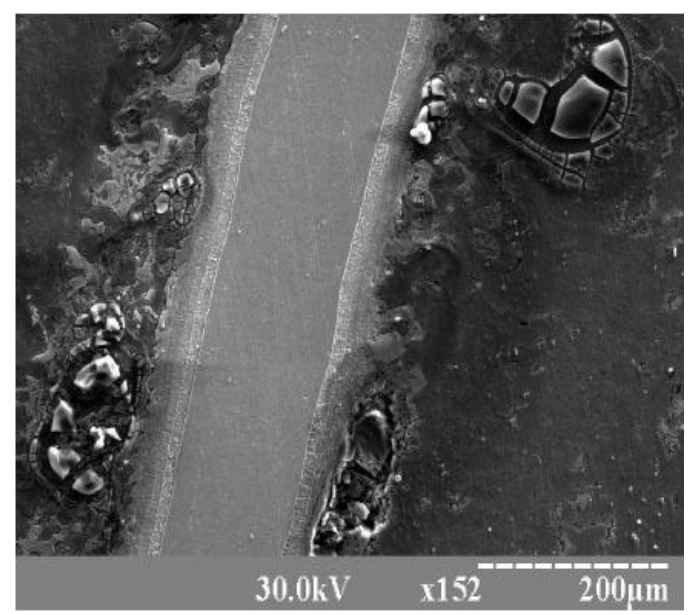

Figure (4): Aluminum-Brass-Aluminum at $540^{\circ} \mathrm{C}$ for 10 minutes holding time. 


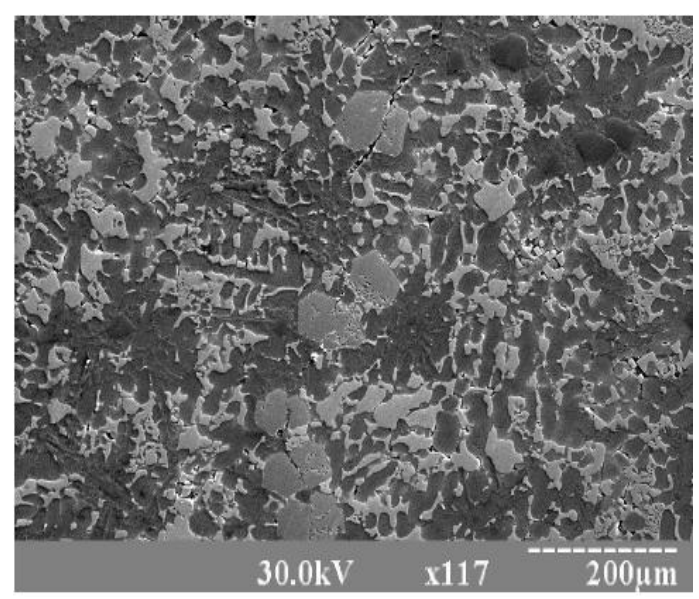

Figure (5): More dissolution of brass ply at $5400 \mathrm{C}$ for 30 minutes holding time.

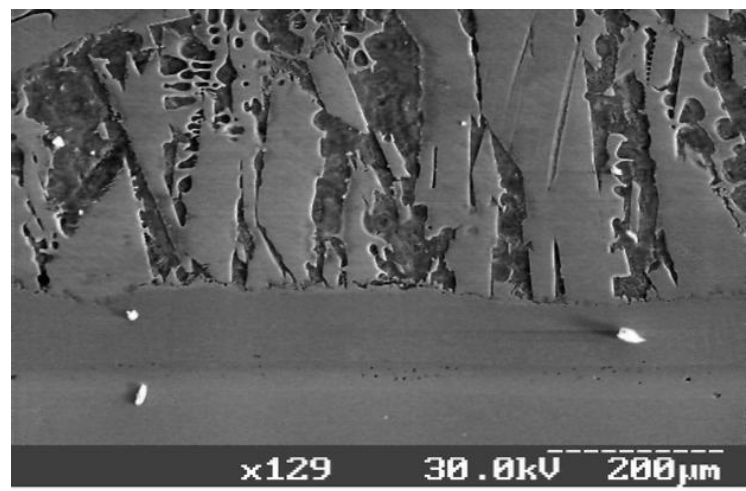

Figure (6): Outer ply resolve $\mathrm{Cu}-\mathrm{Zn}-\mathrm{Al}$, interphase enriched with $\mathrm{Al}$ and $\mathrm{Cu}$, but less $\mathrm{Zn}$, and delocalized zone of interest 60\% $\mathrm{Cu}$ and $40 \% \mathrm{Al}$ (light)while $40 \% \mathrm{Cu}$ and $60 \% \mathrm{Al}$ (dark).

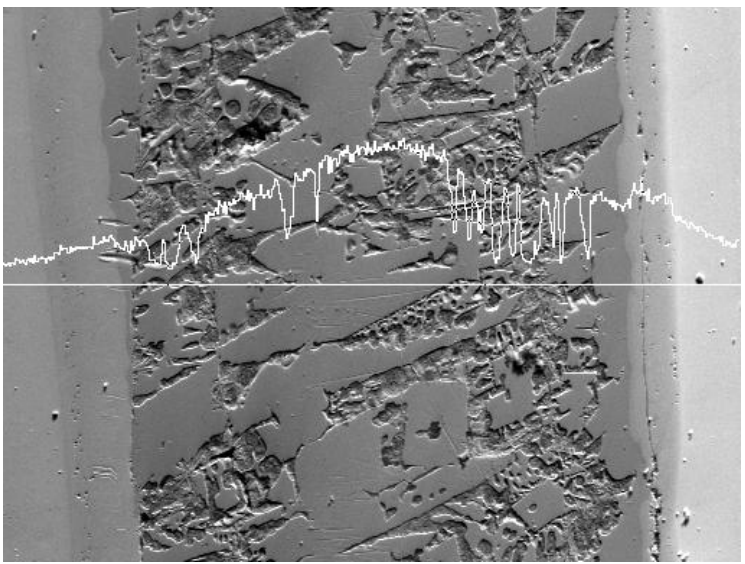

Figure (7): Transverse segregation morphology of main alloying elements, Copper, zinc and aluminum are obtained via EDS for Cu distribution. 


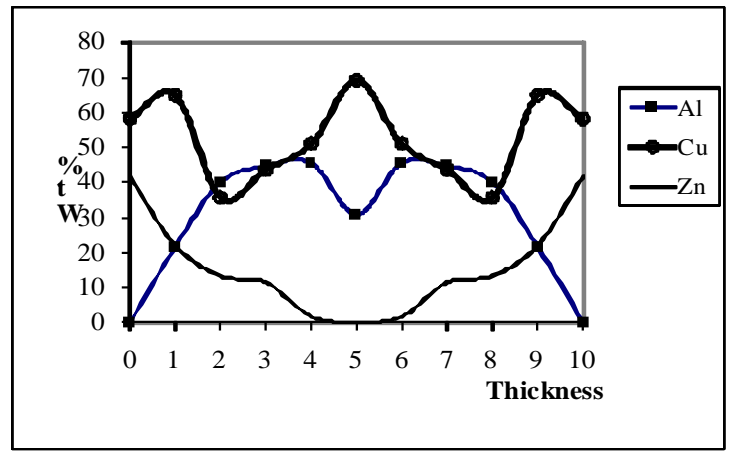

Figure (8): Transverse segregation morphology of main alloying elements, Copper, zinc and aluminum are obtained via EDS for $\mathrm{Cu}, \mathrm{Zn}$ and $\mathrm{Al}$ distribution.

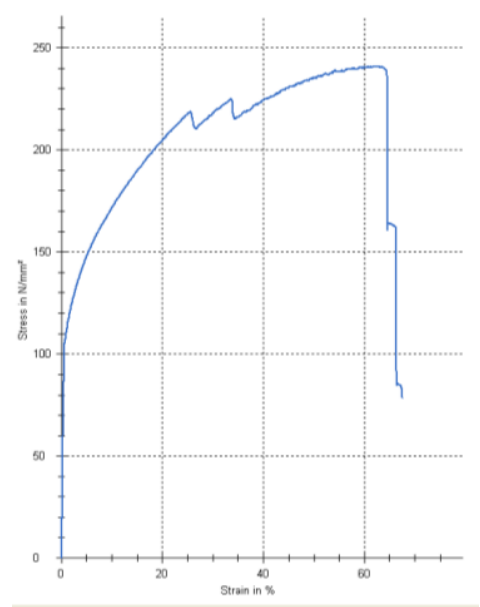

Figure (9): The resulting mechanical properties of Al-Brass-Al hot pressed sample at $540^{\circ} \mathrm{C}$ for $45 \mathrm{~min}$. holding time and a constant pressure of $50 \mathrm{MPa}$

Table (1): An EDX analysis for the different areas of interest such as; the outer surface, the two different interfaces, the two different intermetallic enriched and the center of the sample:

\begin{tabular}{|l|c|c|c|}
\hline \multirow{2}{*}{$\begin{array}{c}\text { SITES OF BONDING } \\
\text { MECHANISMS }\end{array}$} & \multicolumn{3}{|c|}{ Weight Percent (Wt. \%) } \\
\cline { 2 - 4 } $\begin{array}{l}\text { 1- THE OUTER } \\
\text { SURFACE }\end{array}$ & 52.24 & 41.74 & 6.02 \\
\hline $\begin{array}{l}\text { 2- The Interphase } \\
\text { - First Interface }\end{array}$ & 65.03 & 22.05 & 21.62 \\
-Second Interface & 35.67 & 13.35 & 40.12 \\
\hline $\begin{array}{l}\text { 3- Intermetallic } \\
\text { Al - enriched zone }\end{array}$ & 43.7 & 11.55 & 44.75 \\
Cu - enriched zone & 51.09 & 1.77 & 45.61 \\
\hline 4- The Center & 69.18 & 0 & 30.82 \\
\hline
\end{tabular}




\section{Conclusions:}

Engineering of copper zinc aluminum alloy established through hot isostatic pressing. Two different composite materials established in macroscopic scale, lamellar structure and hybrid structure composite. The way these foils stacked as well as hipping parameters induce macroscopic aspects as well as microscopic aspects. Transient liquid phase bonding (TLP) implies that Equilibrium State of the joint region is solid. The route, by which solidification can be achieved, can involve up to four related phenomena. The diffusion into the joint metals is mainly temperature, pressure and time dependent. Brass-Aluminum system can be TLP bonded at $540^{\circ} \mathrm{C}$ using copper zinc alloy. The kinetics of TLP bonding is dependent on the rate of removal of the MPD from the interlayer which in this case is zinc. The process relies on diffusion onto the bulk that leading to intermetallic formation.

The intermetallic formation is now being considered within the bulk matrix of the central plies. $\mathrm{Cu}$-enriched followed by Al-enriched intermetallics are formed within the bulk matrix with continually removal of the MPD from the interlayer to outer ply. Evaporation of the interlayer is a function of the thickness of the interlayer as well as the total area to the bonded. The interface is now being considered with two areas of interest as completely bonded. The rate at which the interface moves is then generally controlled by time taken for intermetallic to grow. Extrusion rate depends on the viscosity of the liquid interlayer.

For the range of viscosities expected for interlayer materials, restriction of flow will be insignificant except for very large joint sections. Rapid reduction of the interlayer width can be achieved by squeezing out the liquid up to a limit imposed by surface tension. Transient liquid phase bonding (TLP) process is now being considered for Cu-Zn-Al system that established for shape memory alloy. Copper based shape memory alloy is now being considered by TLP as well as HIPing process as a new emerging engineering process. This phenomenon established at $540^{\circ} \mathrm{C}$ for a constant pressure of $50 \mathrm{MPa}$ and a holding time of 45 minutes. The mechanical properties of copper based shape memory alloy established with clear ductility as well as hardening behavior dominated by composite processing. Hipping process with TLP induced shape memory alloy for commercial applications.

\section{References:}

[1] MacDonald, W. D. and Eagar, T. W., in Proc. TMS Symp. Metal Science of Joining, Cincinnati p. 93

[2] MacDonald, W. D. and Eagar, T. W., Annu. Rev. Mat. Sci. 22:23

[3] Worden K. Bullough W. A., Haywood J., Smart technologies, World Scientific (2003), pp.109-135

[4] Hodgson D. E. , Shape Memory Applications, Inc., Wu M. H., Memry Technologies, and Biermann R. J., Harrison Alloys, Inc., http://web.archive.org/ web/20030605085042/ http://www. sma-inc.com/SMAPaper.html

[5] Van Humbeeck J., Cederstrom J., "The present state of shape memory materials and barriers

still to be overcome", The first international conference on shape memory and superelastic technologies, March 1994, pp. 1-6. 
[6] Geiger, G. H. and Poirier, D. R., transport Phenomena in Metallurgy, $2^{\text {nd }}$ printing, Addison-Welding, p.491 (1980)

[7] Divecha, A. P., Farrando, W. A., Hesse, P. W. and Karmarker, S. D., U.S. Patent \# 4,958,763, (1990)

[8] Worden K. Bullough W. A., Haywood J., Smart technologies, World Scientific (2003), pp. 109-135.

[9] B. M. Rabeeh, M. E. Shamekh, and M. T. Sallam, "Low Temperature Transient Liquid Phase Bonding of Copper-Aluminum Laminated Composites", Proceeding of the $9^{\text {th }}$ Applied Mechanics and Mechanical Engineering Conference, AMME Conf. 16-18 May, 2000, Cairo, Egypt.

[10] Li, M.G., D.Q. Sun, X.M. Qiu, D.X. Sun, S.Q. Yin Effects of laser brazing parameters on microstructure and properties of TiNi shape memory alloy and stainless steel joint Materials Science and Engineering A 424 (2006) p. 17-22 